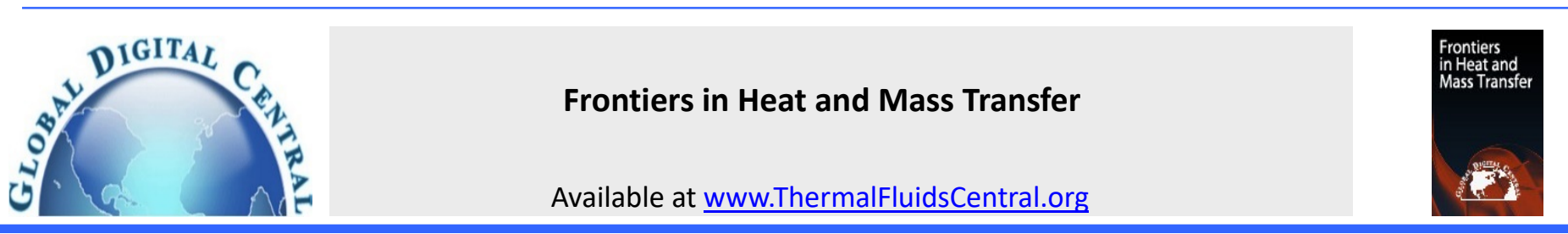

\title{
EXPERIMENT STUDY ON THE BOILING HEAT TRANSFER OF LIQUID FILM IN A ROTATING PIPE
}

\author{
Wenlei Lian, Zijian Sun, Taoyi Han and Yimin Xuan* \\ Key Laboratory of Thermal Management and Energy Utilization of Aircraft, Ministry of Industry and Information Technology, Nanjing \\ University of Aeronautics and Astronautics, Nanjing 210016, China
}

\begin{abstract}
An experimental facility is developed to investigate the characteristics of the nucleate boiling heat transfer in a rotating water film. The High speed photography technique is used to visualize the flow field of the rotating water film. Along with the bubble photographs, the centrifugal acceleration, heat flux into the film, and the heat transfer coefficient are calculated to learn the heat transfer characteristics of the water film. It is found that the boiling heat transfer coefficient decreases with the increment of heat flux. The heat transfer coefficient increases with acceleration increasing from $20 \mathrm{~g}$ to $60 \mathrm{~g}$, but show no obvious increase from $60 \mathrm{~g}$ to $120 \mathrm{~g}$.

Keywords: rotating pipe, water film, visualization, boiling heat transfer
\end{abstract}

\section{INTRODUCTION}

As first discovered by Gray (1969), rotating heat pipes are known as highly effective heat transfer devices. An axially rotating heat pipe (RHP) is a heat pipe rotating about its own longitudinal axis, like all heat pipes (Senthilkumar et al., 2012; Wu et al., 2012, Kumaresan and Venkatachalapathy, 2012; Petrucci and Faghri, 2018), it transfers heat by evaporating the working fluid at the heating section and condensing the vapor at the cooling section(Vasiliev and Khrolenok, 1976; Larkin, 1983; Zhang et al., 2013; Chen et al., 2017, At low rotational speeds, the liquid flow in a horizontal rotating heat pipe is only partially annular due to gravity, and becomes fully annular only at centrifugal acceleration greater than about 20g (Peterson, 1994, Because of its excellent heat transfer capacity, the rotating heat pipe is widely used in machining process. Ponnappan et al, 2013) found that efficient heat dissipation of airborne equipment, such as a combined power pack, can be realized by using a rotating heat pipe. Gilchrist et al, 2009) found that redundant heat from lubricating oil can be absorbed and transferred to the surface of the fairing in a high efficiency to achieve the purpose of anti-icing by using a rotating pipe. The thermal control system based on RHPs is featured with a simple structure, stable performance and high heat transfer efficiency. However, the development of this technology is seriously restricted because the lack of understanding of boiling heat transfer. Many experiments and theoretical analyses have been conducted to investigate the boiling heat transfer characteristics of rotating heat pipes. Faghri (1995) found that nucleate boiling inside the liquid film becomes the dominant factor in the heat transfer of the liquid film when the heat flux transferred by the liquid film is high enough, meanwhile the effect of convection on heat transfer can be ignored. Ulucakli and Merte (1990) studied the effects of liquid supercooling, superheat of wall and centrifugal acceleration on boiling inside liquid film in a rotating pipe, indicating that under certain conditions, the boiling inside the film would be restrained with the increase of rotating speed. With the increase of centrifugal acceleration, the same phenomenon in a rotating pipe was also found by other scholars (Koerner, 1970; Song et al., 2004, Song et al, 2004, 2008) pointed out that although no nucleate boiling was found in the rotating pipe with a centrifugal acceleration of about $600 \mathrm{~g}$, the basis for the determination of boiling inhibition was not clear. In terms of theoretical analysis, according to our previous work, the impact of parameters such as the heat transfer rate, rotational speed, and the fluid loading on the performance of the RHP were examined.

Previous studies mainly focused on figuring out that what may influence the heat transfer capacity of rotating heat pipes, such as centrifugal acceleration, heat flux and fluid loading. However, the relationship between heat transfer capacity and the characteristics of boiling inhibition in rotating heat pipes is rarely studied. The heat transfer capacity of rotating heat pipes is affected seriously by the heat transfer efficiency of the liquid film in the evaporation section. Therefore, it is of great value for the work to find out the Characteristics of boiling inhibition and the resulting heat transfer performance. With the development of high-speed cameras, visualization techniques have been used by more and more researchers to discuss the boiling heat transfer characteristics of liquids. Some scholars (Situ et al., 2004; Suhas et al., 2019) used high-speed photography to measure the bubble departure frequency, bubble lift-off diameter, and bubble dynamics in forced convection subcooled boiling. In the present work, the high-speed photography technique is adopted to visualize the boiling structure of the liquid film, while input heat flux and temperature distribution are to be monitored to learn the heat transfer coefficients under different operation conditions. It is expected that the present work may provide a deeper understanding of the boiling heat transfer of the liquid film in a rotating pipe, and be used for estimating the performance of RHPs in order to optimize their design.

*Corresponding author: ymxuan@nuaa.edu.cn 


\section{EXPERIMENTAL RIG}

An experimental facility is set up to learn the boiling heat transfer within the liquid film in an axially rotating pipe, which consists of the following parts: 1) Mechanical support system and drive motor; 2) Test rotating pipe; 3) Working medium circulation system; 4) Data acquisition system. Figure 1 shows a schematic diagram of the present test rig. The details of the experimental system are discussed below.

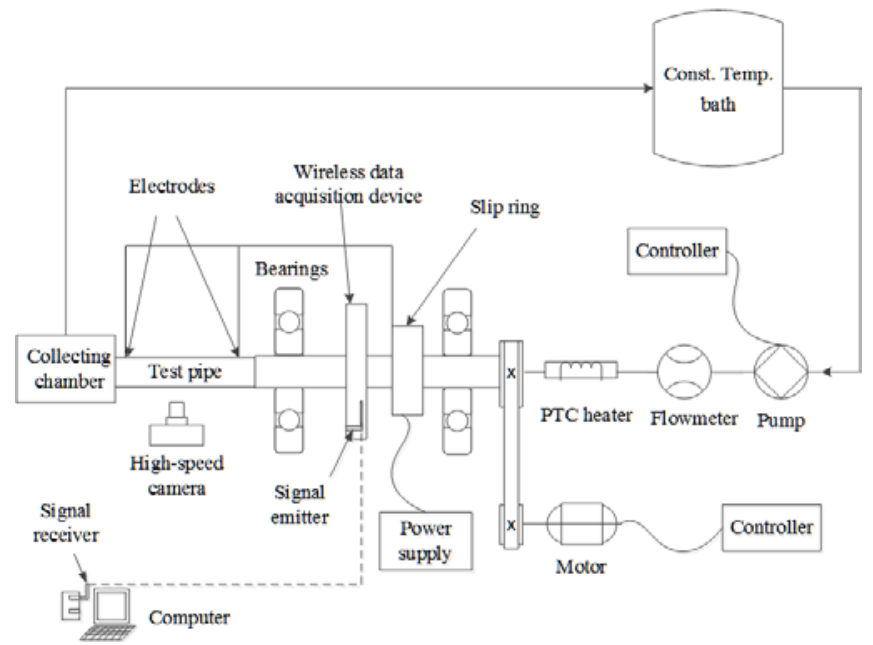

Fig. 1 Schematic of the test rig

\subsection{Rotational control}

The rotating pipe is driven by using a $3.7 \mathrm{KW}$ DC electric motor with a controller (Goodriver 300, Invt Electric Co., Ltd, By using a pair of Synchronous Pulley, the motor is connected to a drive shaft which is screwed on the end of the rotating pipe. A transparent quartz pipe is installed on the drive shaft by using a pair of flanges. The rotating part is mounted in a pair of ball bearings which are fixed on a vibration isolation platform. Figure 2 shows the photograph of the main test installation. During the experiments, the rotational part is shielded by using a cover for safety. The vibration in this experiment is composed of two parts: the motor contributes a part of the vibration; During rotation, the micro-deformation of the rotating pipe contributes to the vibration of the other part. The vibration caused by micro-deformation is a shared phenomenon of all rotating heat pipes, and such vibration should not be classified as uncertainty. Therefore, the main source of uncertainty induced by vibration in this experiment is the vibration of the motor. In order to minimize the vibration caused by motor, the experiment was conducted on a self-balancing platform. During the experiment, the vibration introduced by the motor is absorbed and balanced by the selfbalancing platform, which reduces the uncertainty introduced by the vibration. Compared with centrifugal acceleration and heat flux, the effect of vibration is negligible.

\subsection{Test rotating pipe}

As shown in Fig. 3, the rotating part consists of a drive shaft and a quartz pipe. The drive shaft is made of steel with an inner sleeve made of polytetrafluoroethylene (PTFE, The inner taper of the drive shaft is $1^{\circ}$ and the total length of it is $350 \mathrm{~mm}$. The drive shaft and the quartz pipe are connected by a pair of flanges. A PTFE gasket is employed as a buffer and heat insulation between the quartz flange and the mental flange, protecting the quartz flange from the rigid collision and reducing the heat loss from the quartz pipe to the metal part. One end of the quartz pipe is inserted into the drive shaft with a buffer filled between them to protect the quartz pipe. A rubber gasket is squeezed at the end of quartz pipe to prevent leakage of liquid. A ring-shaped baffle is used to prevent the water from contacting with the heating film.

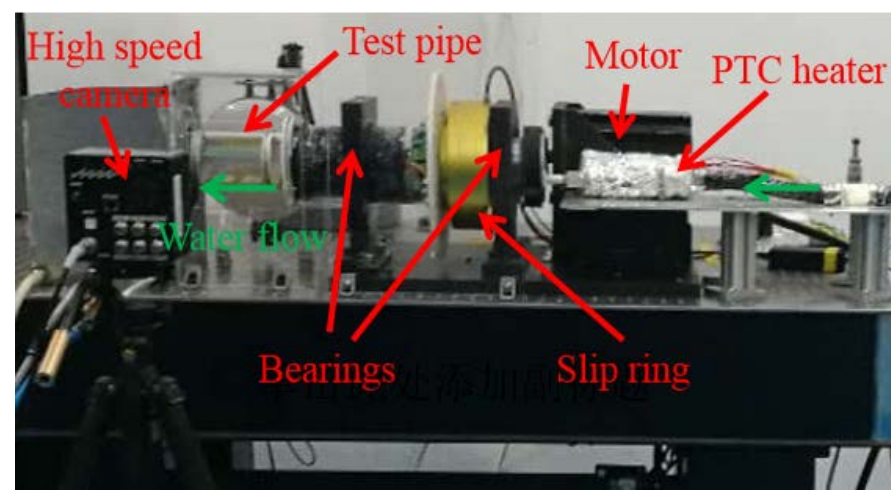

Fig. 2 Photograph of the main test installation

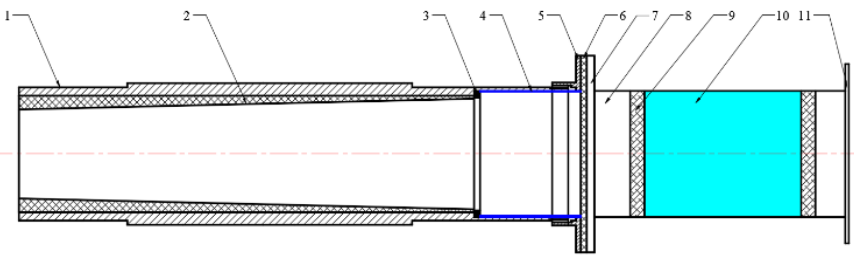
1. Drive draft
2. PTFE lining
3. Rubber gasket
4. Buffer
5. Metal flange 6. PTFE gasket 7. Quartz flange
8. Quartz
pipe 9. Electrodes 10. Transparent heating film
11. Baffle

Fig. 3 Schematic of the rotating part

Figure 4 shows the photograph of the quartz pipe. The outer diameter of the quartz pipe is $80 \mathrm{~mm}$ and the inner diameter is $72 \mathrm{~mm}$. The outer surface of the quartz pipe is coated with a transparent ITO heating film. The length of the coating area is $120 \mathrm{~mm}$ and the electrodes are planted on two ends of the heating film. An air-cooled slip ring is employed to supply power to the heating film. A thin liquid film along the inner wall of the pipe can be maintained during the operation at centrifugal accelerations greater than about $20 \mathrm{~g}$.

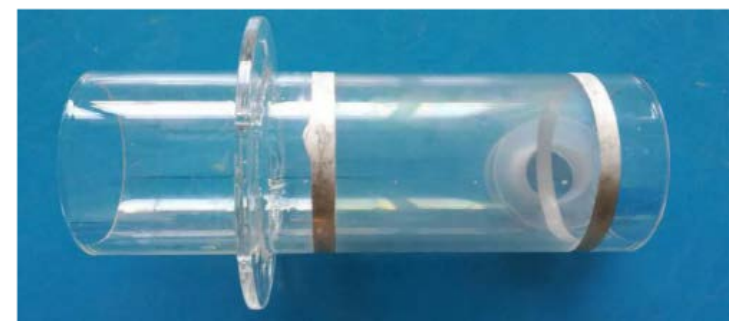

Fig. 4 Photograph of the quartz pipe

\subsection{Working medium circulation system}

A high temperature bath and a pump are used to circulate heat water through the test section. Considering the heat loss through the pump and tubes, a PTC heater is introduced to reheat the water, making its temperature close to the saturation temperature before entering the rotating part. Then the water is heated to boiling by the ITO coating at the test section. Then the boiled water flows out of the rotating pipe with the help of the centrifugal force, being collected by a chamber and finally return to the high temperature bath to form a loop.

\subsection{Data acquisition}

In order to learn the boiling characteristics of the rotating water film. During operation, the centrifugal acceleration, water flow rate, 
temperature of water and the heat flux into the water film, heat transfer coefficient, etc. should be obtained, as well as the bubble photographs under different operation conditions. The centrifugal acceleration can be calculated by

$$
a=\left(\frac{2 \pi N}{60}\right)^{2} r_{0}
$$

Where $N$ is the rotational speed and $r_{0}$ is the inner diameter of the quartz pipe. The rotational speed is measured by using a non-contact digital tachometer (UT372, TOPLIA) with an accuracy of $\pm(0.04 \%+2$, The RPM corresponding to the centrifugal acceleration is shown in the table 1.

Table 1. The correspondence between centrifugal acceleration and

\begin{tabular}{|c|c|c|c|c|c|c|}
\multicolumn{7}{c|}{ rotational speed } \\
\hline Acceleration(g) & 20 & 40 & 60 & 80 & 100 & 120 \\
\hline $\begin{array}{c}\text { Rotational } \\
\text { speed(rpm) }\end{array}$ & 705 & 997 & 1221 & 1410 & 1576 & 1727 \\
\hline
\end{tabular}

The temperature of water and the wall of the rotating pipe are measured by K-type thermocouples. The data are recorded by a data acquisition module on a panel being mounted on the shaft and rotating with the rotating part. The thermocouple signals are then transferred through radio to a remote receiver connected to the computer, so that the data are read simultaneously during the operation. The heat flux added to the water can be calculated by

$q=\frac{\lambda}{r_{0}} \frac{T_{0}-T_{1}}{\ln \left(r_{1} / r_{1}\right)}$

where $r_{0}$ represents the outer diameter of quartz pipe, $T_{0}$ and $T_{1}$ are the temperature of inner and outer wall of the quartz pipe, relatively. $\lambda$ is the thermal conductivity of quartz, which can be calculated by

$\lambda=1.34143+0.00111\left(\frac{T_{0}+T_{1}}{2}\right)$

The heat transfer coefficient can be calculated by

$$
h=\frac{q}{T_{0}-T_{\mathrm{s}}}
$$

where $T_{s}$ is the saturation temperature of water, and $T_{0}-T_{s}$ represents the superheat degree of the inner wall of the quartz pipe. The bubble photographs under different operation conditions are recorded by using a high-speed camera (UX100, Photron Fastcam Mini) with a maximum shooting speed of $200000 \mathrm{fps}$ and a maximum resolution of $1024 \times 1280$. The camera is equipped with a Nikon lens with an adjustable focal length, as well as a coarse adjustment wheel and a fine adjustment wheel. The shooting area is illuminated by using a $100 \mathrm{~W}$ photography lamp with 266-bead LED evenly arranged on the lamp panel. The obtained image data is transmitted to the computer via the data cable, recorded and processed by the Photron Fastcam Viewer.

\section{MEASUREMENT UNCERTAINTY}

The temperature readings have an error of $\pm 0.125^{\circ} \mathrm{C}$ and the uncertainty of the flow rate reading is $\pm 1 \%$ of full scale. Since the heat flux and the heat transfer coefficient are determined by Eq, 2) and Eq , 4), relatively. The major source of uncertainty in the heat flux and heat transfer coefficient is due to the uncertainty of the flow rate as well as the temperatures measured. Uncertainties for results calculated from the measured values are determined by

$$
\frac{\Delta y}{y}=\sum_{i=1}^{n}\left|\frac{\partial \ln f}{\partial x_{i}}\right| \Delta x_{i}
$$

Where $y$ is the calculate d value and $\Delta y$ is the uncertainty of the value, $X_{i}$ is the value by direct measurement, $\Delta x_{i}$ is the uncertainty of the value by direct measurement, $f$ is a formula using $x$ on $y$. The experiment uncertainties in measured and calculated parameters are summarized in Table 2.

Table 2 Uncertainties of measured and calculated parameters

\begin{tabular}{|c|c|}
\hline Parameter & Uncertainty \\
\hline Diameter & $\pm 0.02 \mathrm{~mm}$ \\
\hline Temperature & $\pm 0.125^{\circ} \mathrm{C}$ \\
\hline Volume flow rate & $\pm 1 \%$ \\
\hline Heat flux & $\pm 1.17 \%$ \\
\hline Heat transfer coefficient & $\pm 5.62 \%$ \\
\hline
\end{tabular}

\section{RESULTS AND DISCUSSIONS}

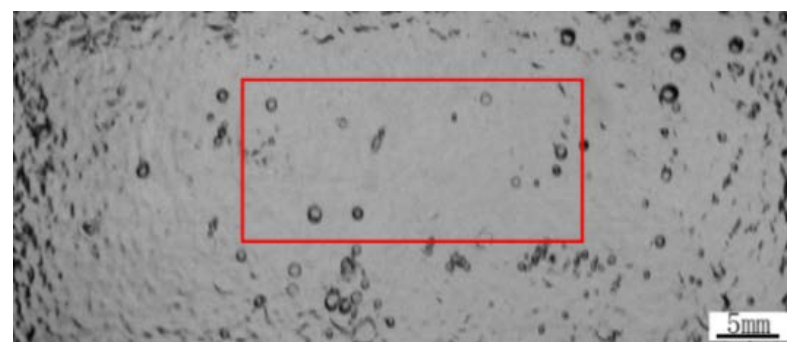

$P=1300 \mathrm{~W}$

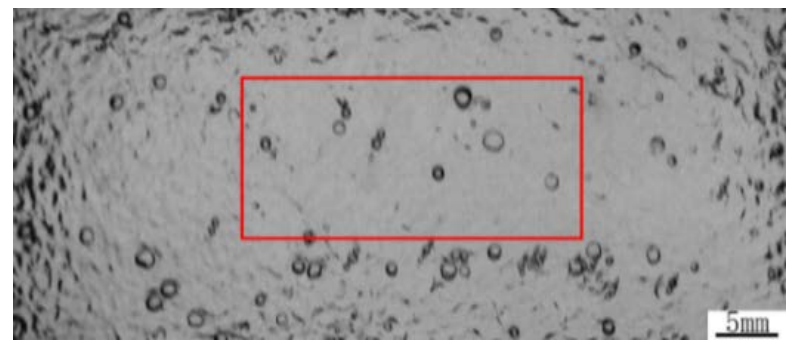

$P=1600 \mathrm{~W}$

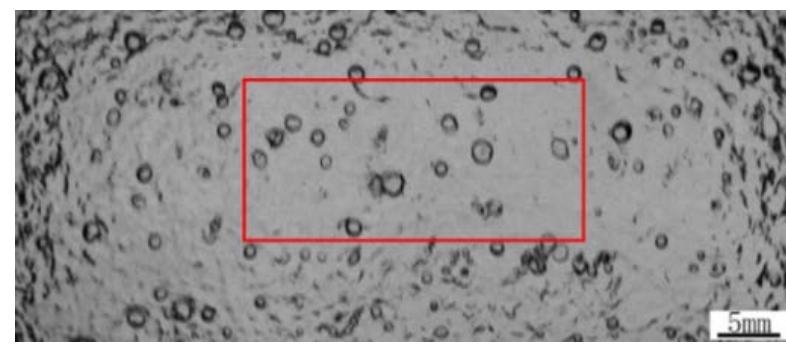

$P=2000 \mathrm{~W}$

Fig. 5 Bubble photographs inside water film at different heating power $(a=40 \mathrm{~g})$ 
The experiments are carried out at centrifugal acceleration $a$ of 20 $\mathrm{g}$ to $120 \mathrm{~g}$ (which leads to a fully annular flow of the liquid inside the rotating pipe), and input heating power $p$ of $1300 \mathrm{~W}$ to $2000 \mathrm{~W}$. The volume flow rate of water is kept at $0.18 \mathrm{~m}^{3} / \mathrm{h}$. The tests are started by flowing the hot water first and then spinning the test pipe at the desired speed followed by the application of the heat input to the test section. The water is heated close to boiling before it enters into the rotating pipe and is heated to boiling by the ITO film at the test section. The images of boiling procedure in the water film are recorded by the high-speed camera during the experiments. When the temperature of the water and the wall reach to a steady state, the bubble photographs at the same area are compared for different input heating power, as shown in Fig. 5. Fig. 6 shows the bubble photographs inside the water film under different centrifugal accelerations with the input heating power of $1300 \mathrm{~W}$. Where $V$ is the volume flow rate.

It can be observed that both the number and size of the bubbles decrease with the increase of centrifugal acceleration. This suggests that nucleate boiling is suppressed with the increase of centrifugal acceleration. The same phenomenon is observed in other working conditions.

It is well known that the heat from a wall into a water film is carried away in three forms: heat conduction, convective heat transfer and boiling heat transfer. During these forms, the boiling can only be induced with enough heat. When convective or nucleate boiling occurs, the heat carried away by conduction can be ignored. This means that the enhancement of one form of heat transferring will lead to the weakening of others with a given heat entering a film. According to our previous work (Lian, 2016), the convection in the evaporation section of a rotating heat pipe would be enhanced with the increase of centrifugal acceleration. Now that the heat originally used to induce boiling diverted by convection, the boiling intensity appears restrained with the increase of centrifugal acceleration. This phenomenon has a great influence on the heat transfer characteristics of rotating liquid film boiling. With a constant input heating power, the heat loss from the quartz pipe increases with the growth of centrifugal acceleration, causing a decrease in the heat flux entering the liquid film by $1.36 \%-9.46 \%$ compared with that when the centrifugal acceleration is $20 \mathrm{~g}$. The range of heat flux corresponding to each input heating power is shown in Table 3.

Table 3 The heat flux into the water film under different heating power

\begin{tabular}{|l|c|c|c|}
\hline$P(\mathrm{~W})$ & 1300 & 1600 & 2000 \\
\hline$Q\left(\mathrm{~W} / \mathrm{m}^{2}\right)$ & $41263-45572$ & $50576-55763$ & $63873-70879$ \\
\hline
\end{tabular}

Fig. 7 shows the heat transfer coefficients under different heat fluxes and centrifugal accelerations. It can be seen that at a constant centrifugal acceleration, the heat transfer coefficient decreases with the increase in heat flux.

The increase in heat flux leads to the increment of superheat degree of the inner wall and the bubble number in the water film. When the input heating power increases form $1300 \mathrm{~W}$ to $1600 \mathrm{~W}$, the superheat degree of the inner wall increases form $6.3^{\circ} \mathrm{C}$ to $8.5^{\circ} \mathrm{C}$ with a growth rate of about $35 \%$. On the other hand, the bubble number in the same area (the red frame in Fig. 5) can be counted and it is found that the growth rate of bubble number is about $14 \%$. It may be concluded that the increase in bubble number density leads to a smaller increase in the heat flux transferred by the bubble, compared to the increase in the superheat degree of the inner wall, which may be the reason why the heat transfer coefficient decreases with the increment of input heating power. The same phenomenon can be observed as the input heating power increases form $1600 \mathrm{~W}$ to $2000 \mathrm{~W}$.

A set of experiments was also conducted under the same working conditions except that the volume flow rate into the rotating pipe was changed to $0.35 \mathrm{~m}^{3} / \mathrm{h}$. Figure 8 shows the photographs inside water film under the condition of flow rate of $0.35 \mathrm{~m}^{3} / \mathrm{h}$ and heating power of $1300 \mathrm{~W}$.

The laws observed from the bubbles photographs inside the water film in this series of experiments share similar characteristics with the laws obtained under the working condition with the volume flow rate of $0.18 \mathrm{~m}^{3} / \mathrm{h}$ : the number and size of bubbles decrease with the increase of centrifugal acceleration.

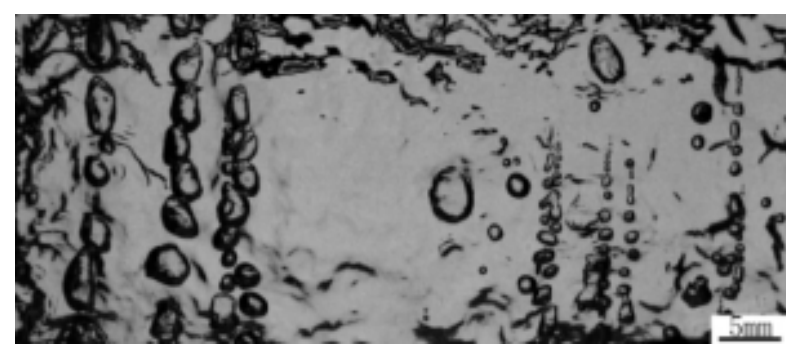

$$
a=20 \mathrm{~g}
$$

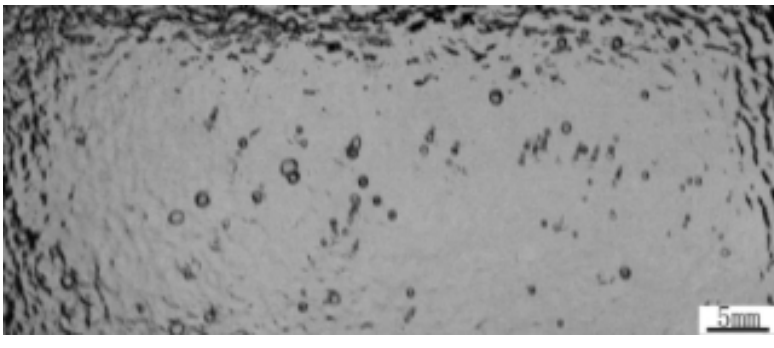

$a=40 \mathrm{~g}$

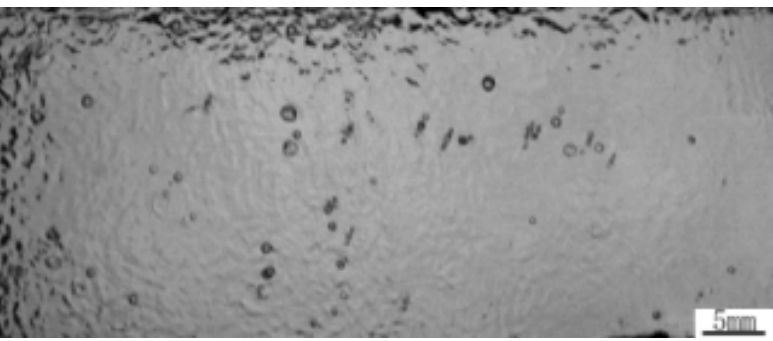

$a=60 \mathrm{~g}$

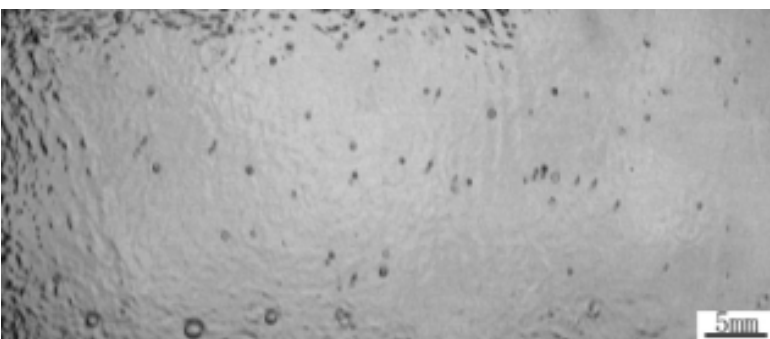

$a=80 \mathrm{~g}$

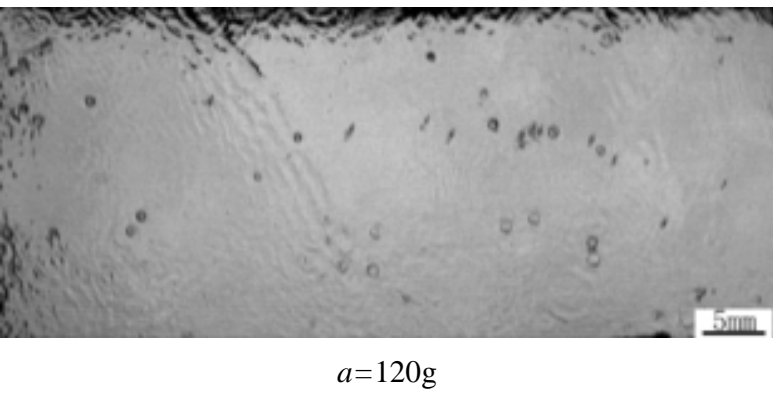

Fig. 6 Bubble photographs inside water film at different acceleration $\left(P=1300 \mathrm{~W}, V=0.18 \mathrm{~m}^{3} / \mathrm{h}\right)$ 


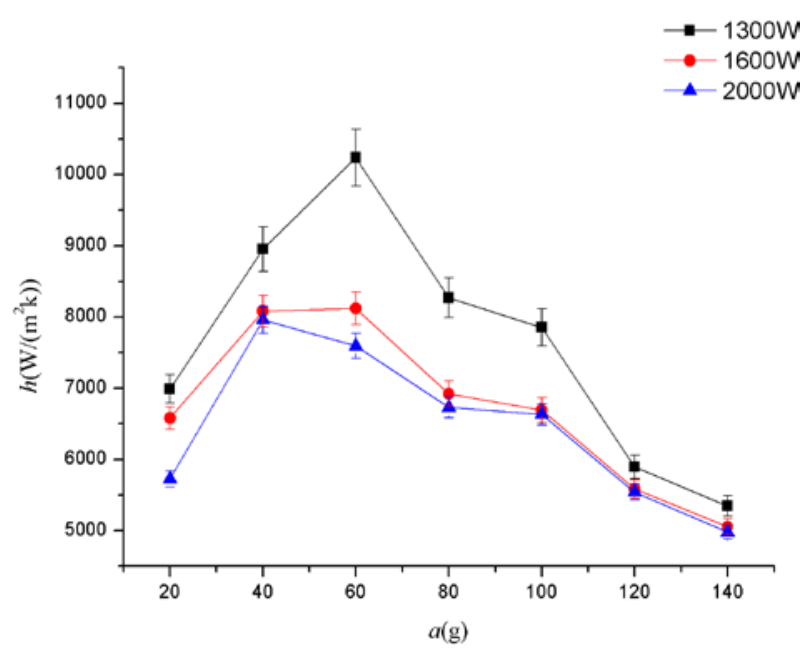

Fig. 7 Heat transfer coefficients under different heat fluxes and accelerations, $V=0.18 \mathrm{~m}^{3} / \mathrm{h}$
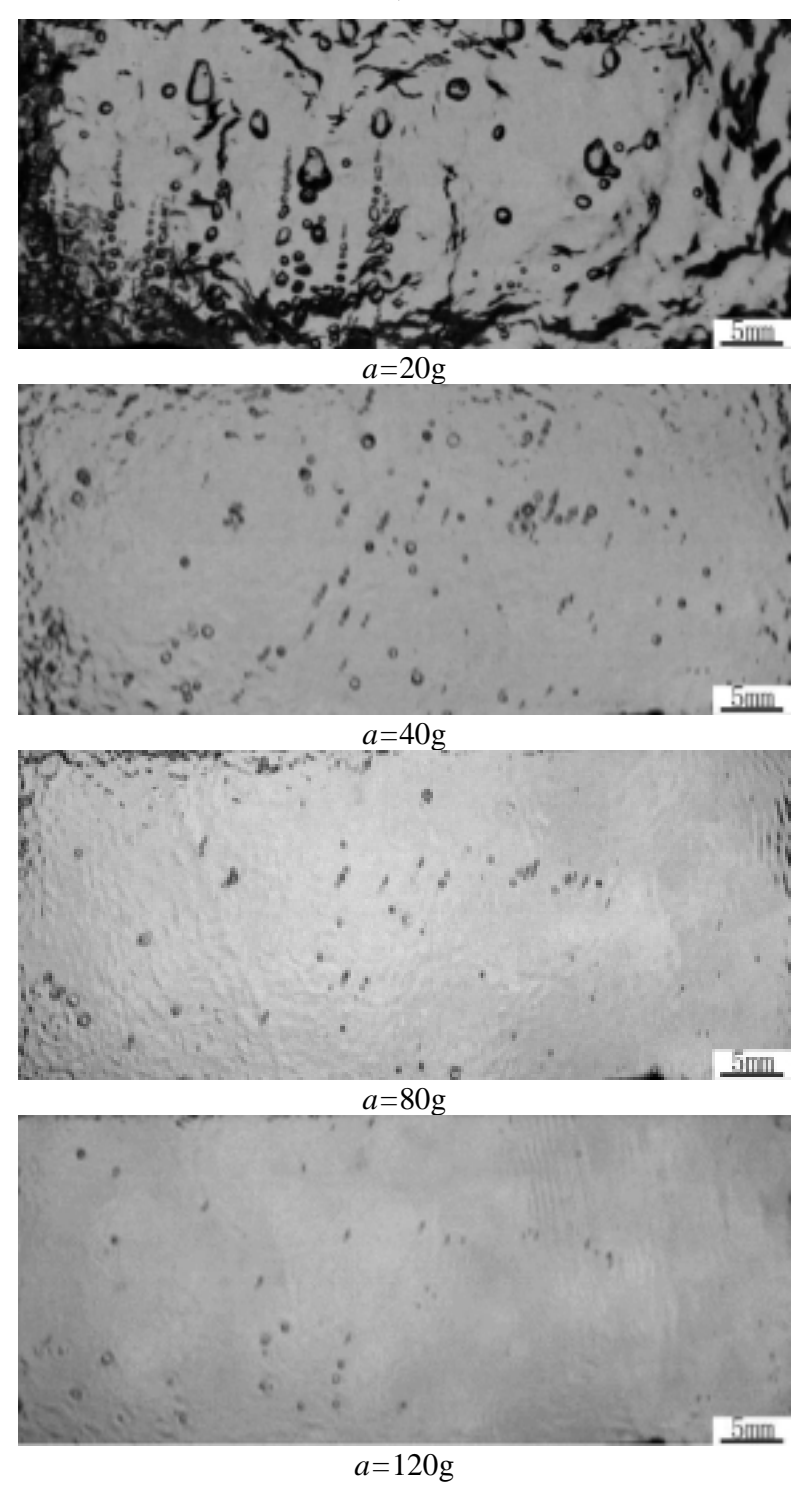

Fig. 8 Bubble photographs inside water film at different acceleration $\left(P=1300 \mathrm{~W}, V=0.35 \mathrm{~m}^{3} / \mathrm{h}\right)$

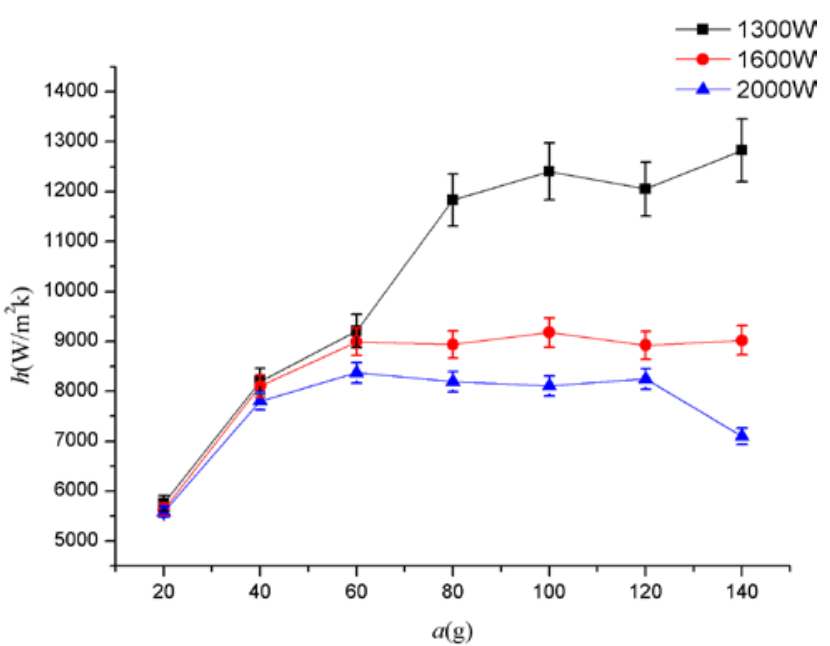

Fig. 9 Heat transfer coefficients under different heat fluxes and accelerations, $V=0.35 \mathrm{~m}^{3} / \mathrm{h}$

Figure 9 shows the relationship between different centrifugal accelerations and heat transfer coefficient under this flow rate. It is observed that the boiling heat transfer characteristics of the rotating liquid film with the volume flow rate of $0.35 \mathrm{~m}^{3} / \mathrm{h}$ is similar to that with the volume flow rate of $0.18 \mathrm{~m}^{3} / \mathrm{h}$, except that there is no obvious decrease of the heat transfer coefficients after the peak values. The increase of the flow rate of liquid results this phenomenon. According to our previous work, a further enhancement on convection caused by centrifugal acceleration will appear with the increase of the liquid loading of a rotating heat pipe.

This reveals that the heat transfer contribution ratio of convection is increased in series of experiments with the volume flow rate of $0.35 \mathrm{~m}^{3} / \mathrm{h}$. In the stage after the peak, the effect of boiling inhibition on heat transform transfer gradually appeared with the decrease of the increment of convection enhancement. Compared with the experiments with the volume flow rate of $0.18 \mathrm{~m}^{3} / \mathrm{h}$, the convection heat transferring inside the liquid film is in a relatively vigorous stage. The vigorous convection heat transferring results that the negative contribution of boiling inhibition can only stop the curve of heat transfer coefficient rising.

\section{CONCLUSIONS}

An experimental facility has been developed to investigate the boiling heat transfer within the liquid film during the operation of an axially rotating pipe. The bubble paragraphs were recorded by a high-speed camera, and the heat transfer coefficients have been calculated by using the temperature values, which were used to determine the heat transfer characteristics under different operation conditions. It is found that at a constant centrifugal acceleration, the heat transfer coefficient decreases with the increase in heat flux, which may be caused by the fact that the increase in bubble number density leads to a smaller increase in the heat flux transferred by the bubble, compared to the increase in the superheat degree of the inner wall. As the centrifugal acceleration increases, while the boiling is suppressed, the convective heat transfer is enhanced due to lager fluid velocities and thinner water film. The heat transfer coefficient increases with acceleration increasing from $20 \mathrm{~g}$ to $60 \mathrm{~g}$, but show no obvious increase from $60 \mathrm{~g}$ to $120 \mathrm{~g}$ since the suppression of boiling is more obvious at this stage.

\section{ACKNOWLEDGEMENT}

This work is sponsored by the National Natural Science Foundation of China (Grant No. 51606094, 


\section{REFERENCES}

Chen, J., Fu, Y., Gu, Z., Shen, H., and He, Q., 2017, "Study on heat transfer of a rotating heat pipe cooling system in dry abrasive-milling," Applied Thermal Engineering, 115, 736-743.

https://doi.org/10.1016/j.applthermaleng.2016.12.138

Gilchrist, S., Ewing, D., and Ching, C. Y, 2009, "On the design of an aero-engine nose cone anti-icing system using a rotating heat pipe," Journal of Thermal Science and Engineering Applications, 1(2), 022002. https://doi.org/10.1115/1.4000191

Gray, V. H, 1969, “The rotating heat pipe-A wickless, hollow shaft for transferring high heat fluxes,” Proceedings of the ASME/AIChE Heat Transfer Conference, Minneapolis, August 3-6 1969, 1-5.

Koerner, W, 1970, “The Influence of High Acceleration on Boiling Heat Transfer,” Chemie-Ingenieur-Technik, 42(6), 409-414.

Kumaresan, G., and Venkatachalapathy, S, 2012, "A review on heat transfer enhancement studies of heat pipes using nanofluids," Frontiers in Heat Pipes (FHP), 3(4), 043001.

https://doi.org/10.5098/fhp.v3.4.3001

Larkin, B. S, 1983, “An experimental investigation of a low heat flux, wickless heat pipe," Transactions of the Canadian Society for Mechanical Engineering, 7(2), 96-99.

Lian, W., Chang, W., and Xuan, Y, 2016, "Numerical investigation on flow and thermal features of a rotating heat pipe," Applied Thermal Engineering, 101, 92-100.

https://doi.org/10.1016/j.applthermaleng.2016.02.110

Lian, W., and Han, T, 2019, "Flow and heat transfer in a rotating heat pipe with a conical condenser," International Communications in Heat and Mass Transfer, 101, 70-75.

https://doi.org/10.1016/j.icheatmasstransfer.2018.12.004

Peterson, G. P, 1994, “An introduction to heat pipes. Modeling, testing, and applications," Wiley Series in Thermal Management of Microelectronic and Electronic Systems, New York, Chichester: Wiley,| c1994.

Petrucci, M., and Faghri, A, 2018, "Heat pipe turbine vane integration in gas turbine engines," Frontiers in Heat and Mass Transfer (FHMT), 11. Ponnappan, R., He, Q., Leland, J., Ponnappan, R., He, Q., and Leland, J,
1997, "Test results of a high speed rotating heat pipe," In 32nd Thermophysics Conference, p. 2543, https://doi.org/10.2514/6.1997-2543

Senthilkumar, R., Vaidyanathan, S., and Sivaraman, B, 2012, "Experimental analysis of cylindrical heat pipe using copper nanofluid with an aqueous solution of n-Hexanol," Frontiers in Heat Pipes (FHP), 2(3),

Wu, G.W., Chen, S.L, Shih, W.P., 2012, "Lamination and characterization of a polyethylene-terephthalate flexible micro heat pipe," Frontiers in Heat Pipes (FHP), 3(2), 023003. http://dx.doi.org/10.5098/fhp.v3.2.3003

Situ, R., Mi, Y., Ishii, M., and Mori, M, 2004, "Photographic study of bubble behaviors in forced convection subcooled boiling," International Journal of Heat and Mass Transfer, 47(17-18), 3659-3667. https://doi.org/10.1016/j.ijheatmasstransfer.2004.04.005

Song, F., Ewing, D., and Ching, C. Y, 2004, "Experimental investigation on the heat transfer characteristics of axial rotating heat pipes," International Journal of Heat and Mass Transfer, 47(22), 4721-4731. https://doi.org/10.1016/j.ijheatmasstransfer.2004.06.001

Song, F., Ewing, D., and Ching, C. Y, 2008, "Heat transfer in the evaporator section of moderate-speed rotating heat pipes," International journal of heat and mass transfer, 51(7-8), 1542-1550. https://doi.org/10.1016/j.ijheatmasstransfer.2007.07.020

Suhas, B. G., Sathyabhama, A., Veerabhadrappa, K., Suresh Kumar, U., and Kiran Kumar, U, 2019, "Wall heat flux partitioning analysis for subcooled flow boiling of water-ethanol mixture in conventional channel,” Frontiers in Heat and Mass Transfer (FHMT), 13, 16. https://doi.org/10.5098/hmt.13.16

Ulucakli, M. E., and Merte Jr, H, 1990, "Nucleate boiling with high gravity and large subcooling,” 112(2), 451-457 https://doi.org/10.1115/1.2910399

Vasiliev, L. L., and Khrolenok, V. V, 1976, “Centrifugal coaxial heat pipes,” hepi, 293-302.

Zhang, M., Lai, Y., Dong, Y., Jin, L., Pei, W., and Harbor, J, 2013, "Laboratory investigation of the heat transfer characteristics of a twophase closed thermosyphon," Cold regions science and technology, 95, 67-73.

https://doi.org/10.1016/j.coldregions.2013.08.006 